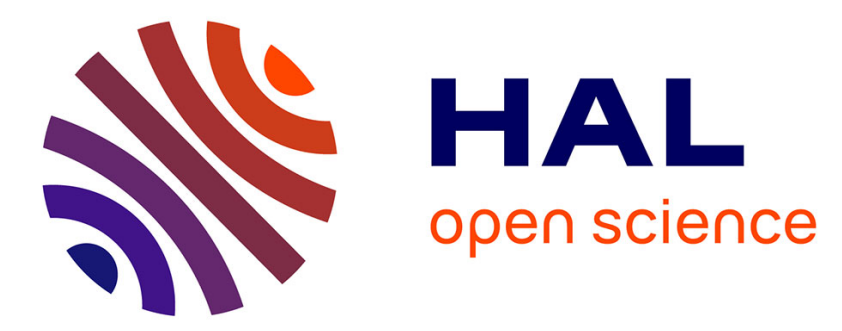

\title{
Mouse $\gamma$-butyrobetaine dioxygenase is regulated by peroxisome proliferator-activated receptor $\alpha$ through a PPRE located in the proximal promoter
}

Gaiping Wen, Hagen Kühne, Christine Rauer, Robert Ringseis, Klaus Eder

\section{- To cite this version:}

Gaiping Wen, Hagen Kühne, Christine Rauer, Robert Ringseis, Klaus Eder. Mouse $\gamma$-butyrobetaine dioxygenase is regulated by peroxisome proliferator-activated receptor $\alpha$ through a PPRE located in the proximal promoter. Biochemical Pharmacology, 2011, 10.1016/j.bcp.2011.04.006 . hal-00703548

\author{
HAL Id: hal-00703548 \\ https://hal.science/hal-00703548
}

Submitted on 3 Jun 2012

HAL is a multi-disciplinary open access archive for the deposit and dissemination of scientific research documents, whether they are published or not. The documents may come from teaching and research institutions in France or abroad, or from public or private research centers.
L'archive ouverte pluridisciplinaire HAL, est destinée au dépôt et à la diffusion de documents scientifiques de niveau recherche, publiés ou non, émanant des établissements d'enseignement et de recherche français ou étrangers, des laboratoires publics ou privés. 


\section{Accepted Manuscript}

Title: Mouse $\gamma$-butyrobetaine dioxygenase is regulated by peroxisome proliferator-activated receptor $\alpha$ through a PPRE located in the proximal promoter

Authors: Gaiping Wen, Hagen Kühne, Christine Rauer, Robert Ringseis, Klaus Eder

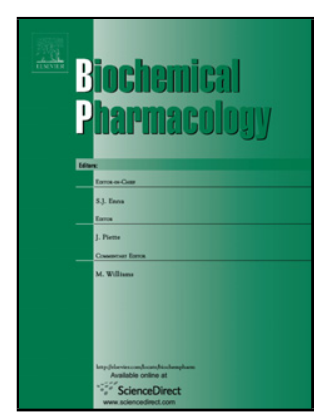

PII: S0006-2952(11)00245-0

DOI: doi:10.1016/j.bcp.2011.04.006

Reference: BCP 10878

To appear in: $\quad B C P$

Received date: $\quad 3-2-2011$

Revised date: $\quad 12-4-2011$

Accepted date: $\quad 18-4-2011$

Please cite this article as: Wen G, Kühne H, Rauer C, Ringseis R, Eder K, Mouse $\gamma$ butyrobetaine dioxygenase is regulated by peroxisome proliferator-activated receptor $\alpha$ through a PPRE located in the proximal promoter, Biochemical Pharmacology (2010), doi:10.1016/j.bcp.2011.04.006

This is a PDF file of an unedited manuscript that has been accepted for publication. As a service to our customers we are providing this early version of the manuscript. The manuscript will undergo copyediting, typesetting, and review of the resulting proof before it is published in its final form. Please note that during the production process errors may be discovered which could affect the content, and all legal disclaimers that apply to the journal pertain. 
1 Mouse $\gamma$-butyrobetaine dioxygenase is regulated by peroxisome 2 proliferator-activated receptor $\alpha$ through a PPRE located in the proximal

7 anstitute of Animal Nutrition and Nutritional Physiology, Justus-Liebig-Universität, 8 Heinrich-Buff-Ring 26-32, 35392 Giessen, Germany

9 binstitute of Agricultural and Nutritional Sciences, Martin-Luther-Universität Halle10 Wittenberg, Von-Danckelmann-Platz 2, 06120 Halle (Saale), Germany

$12 *$ *orresponding author. Tel +641 9939230; fax: + 641 9939239. E-mail address:

13 klaus.eder@ernaehrung.uni-giessen.de. 


\section{A B S T R A C T}

Convincing evidence from studies with peroxisome proliferator-activated receptor (PPAR) $\alpha$ deficient mice suggested that the carnitine biosynthetic enzyme $\gamma$-butyrobetaine dioxygenase (BBD) is regulated by PPAR $\alpha$. However, the identification of BBD as a direct PPAR $\alpha$ target gene as well as its exact regulation remained to be demonstrated. In silico-analysis of the mouse BBD promoter revealed seven putative peroxisome proliferator response elements (PPRE) with high similarity to the consensus PPRE. Luciferase reporter gene assays using mutated and non-mutated serial 5'-truncation BBD promoter reporter constructs revealed that one PPRE located at -75 to -87 relative to the transcription start site in the proximal BBD promoter is probably functional. Using gel shift assays we observed in vitro-binding of PPAR $\alpha / R X R \alpha$ heterodimer to this PPRE confirming that it is functional. In conclusion, the present study clearly shows that mouse BBD is a direct PPAR $\alpha$ target gene and that transcriptional up-regulation of mouse $\mathrm{BBD}$ by $\mathrm{PPAR} \alpha$ is likely mediated by binding of the PPAR $\alpha /$ RXR heterodimer to one PPRE located in its proximal promoter region. The results confirm emerging evidence from recent studies that PPAR $\alpha$ plays a key role in the regulation of carnitine homeostasis by controlling genes involved in both, carnitine synthesis and carnitine uptake.

Keywords: carnitine; $\gamma$-butyrobetaine dioxygenase; peroxisome proliferator-activated receptor $\alpha$; mouse. 


\section{Introduction}

Peroxisome proliferator-activated receptor $\alpha(\operatorname{PPAR} \alpha)$ is a ligand-activated transcription factor that acts as an important regulator of lipid metabolism and energy homeostasis [1]. PPAR $\alpha$ is abundantly expressed in tissues with high rates of fatty acid oxidation such as liver, heart muscle, skeletal muscle, and kidney [2]. Transcriptional regulation of genes by PPAR $\alpha$ is mediated by forming a heterodimer with the retinoid $\mathrm{X}$ receptor (RXR) and subsequent binding of the PPAR $\alpha / R X R$ heterodimer to a specific DNA consensus sequence, called peroxisome proliferator response element (PPRE), present in the promoter, intronic or $5^{\prime}$-untranslated region of target genes [2-6], thereby stimulating the expression of those genes. Proteins encoded by these genes are involved in all aspects of fatty acid catabolism, ketogenesis as well as gluconeogenesis [2]. PPAR $\alpha$ can be activated by either endogenous ligands such as fatty acids, which are released from white adipose tissue during fasting and taken up into tissues during this state $[7,8]$ or exogenous ligands such as fibrates (WY-14,643, clofibrate, fenofibrate, bezafibrate, and gemfibrozil) [7, 8].

Evidence from both in vitro- and in vivo-studies clearly shows that PPAR $\alpha$ also plays an essential role for regulating carnitine homeostasis (reviewed by [9]). For instance, activation of hepatic PPAR $\alpha$ by fibrates or fasting increases hepatic carnitine concentrations [10-13], whereas down-regulation of PPAR $\alpha$ as observed during lactation causes a reduction of hepatic carnitine concentrations [14]. The essential role for PPAR $\alpha$ in regulating carnitine homeostasis is confirmed by the observation that PPAR $\alpha$-deficient mice have markedly reduced carnitine levels in tissues $[11,12,15]$. Carnitine is an essential metabolite that is required for the $\beta$-oxidation of long-chain fatty acids in the mitochondrial matrix [16]. Hence, all tissues that use fatty acids as a fuel source require carnitine for normal function. Carnitine is derived from dietary sources and endogenous biosynthesis [17]. Carnitine biosynthesis involves a complex series of reactions. Lysine in protein peptide linkages provides the carbon backbone of carnitine. It undergoes methylation of the $\varepsilon$-amino group to yield trimethyllysine, 
which is released upon protein degradation. The released trimethyllysine is further oxidised to $\gamma$-butyrobetaine which is then hydroxylated by $\gamma$-butyrobetaine dioxygenase (BBD) to form carnitine [18]. In all mammals, a significant BBD activity is found in the liver [18], and in some species such as in humans, pigs, cats, cows, hamsters, rabbits or Rhesus monkeys also in the kidney $[18,19]$. Other tissues have either no or only a very low activity of BBD [18, 19], and are therefore highly dependent on active carnitine uptake from blood. Delivery of carnitine from plasma into cells is catalyzed by novel organic cation transporters (OCTN), from which the OCTN2 isoform has the highest binding affinity for carnitine and is therefore the physiologically most important carnitine transporter [20,21].

The observation that the alterations in hepatic carnitine concentrations in response to treatment with PPAR $\alpha$ agonists, fasting, lactation or genetic disruption of PPAR $\alpha$ were accompanied by either increased or decreased expression of genes involved in carnitine uptake and biosynthesis like OCTN2 and BBD strongly suggested that these genes are regulated by PPAR $\alpha$. In fact, OCTN2 was recently identified as a direct PPAR $\alpha$ target gene which is transcriptionally regulated by PPAR $\alpha$ through a functional PPRE in the first intron [6]. Based on these observations we hypothesize that BBD is also a target gene of PPAR $\alpha$. This hypothesis is supported by the identification of a putative PPRE in the mouse BBD promoter based on sequence alignment [11]. However, the functionality of this PPRE for the regulation of mouse BBD promoter remains to be established. Furthermore, it has not been addressed whether regulation of mouse BBD by PPAR $\alpha$ may also involve other PPRE located in the BBD promoter region. In the present study, we therefore performed in silico-analysis, reporter gene experiments and gel shift assays to identify functional PPRE in the mouse BBD gene. Our data indicate that mouse BBD is a direct target gene of PPAR $\alpha$ and that transcriptional up-regulation of BBD by PPAR $\alpha$ is mediated by one PPRE located in its promoter region. 
88

89

90 91 92

\section{Materials and methods}

\subsection{Chemicals}

WY-14,643 was purchased from Sigma-Aldrich (Steinheim, Germany).

\subsection{Cell culture}

HepG2 cells, a human hepatoma cell line (DSMZ, Braunschweig, Germany) that is commonly used for transient transfection assays [5], were cultured in RPMI1640 GlutaMax-1 medium (Invitrogen, Karlsruhe, Germany) supplemented with $10 \%$ fetal calf serum (Invitrogen) and $0.05 \mathrm{mg} / \mathrm{mL}$ gentamycin (Invitrogen). Cells were maintained at $37^{\circ} \mathrm{C}$ in a humidified atmosphere of $95 \%$ air and $5 \% \mathrm{CO}_{2}$. Medium was changed every 2 days. For reporter gene experiments, cells were seeded in 96-well culture plate at a density of $4 \times 10^{4}$ per well. Cells were used for transient transfection at a confluence of $70 \%$.

\subsection{In silico-analysis of mouse BBD promoter}

Using cDNA and genomic sequences from NCBI Genbank (Accession number BC019406 and AL691416) an approximately $1.5 \mathrm{~kb}$ fragment of mouse BBD promoter from 1,394 to +94 relative to transcription start site was scanned and analyzed for putative PPRE using the NUBIScan (nuclear receptor binding site scanner; [22]).

\subsection{Generation of mouse BBD promoter reporter constructs}

Six BBD promoter-truncation constructs were designed (Fig. 1 and 2). The 1,488 bp promoter fragment from $-1,394$ to +94 relative to transcription start site (BBD-1,488) containing seven predicted PPRE was PCR amplified from mouse BAC clone RP23-110I8 (imaGene, Berlin Germany). The generated PCR fragment with BglII and XhoI restriction sites introduced at the $5^{\prime}$ and $3^{\prime}$ ends was subcloned into the BglII and XhoI digested 
pGL4.10 [luc2] vector (Promega, Mannheim, Germany) upstream of the luciferase reporter gene, thereby, providing the full-length construct pGL4-BBD-1488 (BBD construct 1). The BBD promoter-truncation constructs pGL4-BBD-1197 (BBD construct 2; from -1,103 to +94) containing six putative PPRE, pGL4-BBD-668 (BBD construct 3; from -574 to +94) containing five putative PPRE, pGL4-BBD-376 (BBD construct 4; from -282 to +94) containing four putative PPRE, pGL4-BBD-232 (BBD construct 5; from -138 to +94) containing three putative PPRE, and pGL4-BBD-164 (BBD construct 6; from -70 to +94) containing two overlapping PPRE were PCR amplified from parental clone pGL4.10-BBD1488 by using different $5^{\prime}$-primers flanking the putative PPRE and a common 3 '-primer. The primer sequences are shown in Tab. 1. The generated PCR products containing two adapters of BglII and XhoI site at the end were subcloned into the BglII and XhoI digested pGL4.10 [luc2] vector upstream of the luciferase reporter gene. The cloned DNA fragments were sequenced to confirm the integrity of the constructs.

In addition, BBD promoter constructs containing 3 copies of either PPRE6, PPRE1 or PPRE3 in front of a mini promoter of the luciferase reporter gene were designed. To generate these, the following oligonucleotides (Eurofins MWG Operon, Ebersberg, Germany) containing either 3X PPRE6, 3X PPRE1 or 3X PPRE3 and two adapters of KpnI and HindIII site were annealed: $3 \mathrm{X}$ mBBD_PPRE6 (forward: 5'-TCGAAATACTCTAATCAGAACAAA GGTCCCGGCATCTAATCAGAACAAAGGTCCCGGCATCTAATCAGAACAAAGGTC CCGGCATGGGGCG-3', reverse: 5'-AGCTCGCCCCATGCCGGGACCTTTGTTCTGATT AGATGCCGGGACCTTTGTTCTGATTAGATGCCGGGACCTTTGTTCTGATTAGAGTA TT-3'), 3X mBBD_PPRE1 (forward: 5'-TCGAAGCTGGGACTGAAGTTCAACGGTAGA ATGCCGACTGAAGTTCAACGGTAGAATGCCGACTGAAGTTCAACGGTAGAATGC CTGTCTC-3', reverse: 5'-AGCTGAGACAGGCATTCTACCGTTGAACTTCAGTCGGCA 
TTTGGTGACCCCTGACAGATTTTTATTTGGTGACCCCTGACAGATTTTTTTAAAA-

3', reverse: 5'-AGCTTTTTAAAAAAATCTGTCAGGGGTCACCAAATAAAAATCTGTC AGGGGTCACCAAATAAAAATCTGTCAGGGGTCACCAAATAATCTT-3'). After annealing, the double stranded DNA fragments were cloned into the KpnI and HindIII digested pGL4.23 [luc2/minP] vector (Promega). After cloning fragments were controlled for the identity of the 3X PPRE by DNA sequencing.

\subsection{Site-directed mutagenesis of BBD promoter reporter constructs}

Mutation constructs were prepared by introducing a mutation in the putative PPRE with Site-Directed Mutagenesis kit according to the manufacturer's protocol (Stratagene Europe, Amsterdam, Netherlands) using the following oligonucleotides: PPRE1mut (forward: 5'-AGACAGGCATTCTㅁCGTäGAACTTCAGTCCCAGC-3', reverse: 5'-GCTGGGACTG AAGTTCtACGGaAGAATGCCTGTCT-3'), PPRE2mut (forward: 5'-TATTTCATTAGTGA CgGTATACgTGACATTCAGGA-3', reverse: 5'-TCCTGAATGTCAçGTATACçGTCACT AATGAAATA-3'), PPRE3mut (forward: 5'-TTTAAAAAAATCTGTCtgGGGaCACCAAA

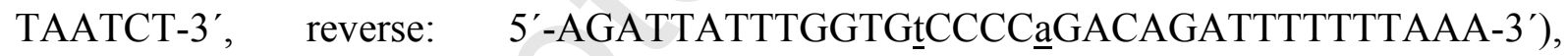
PPRE4mut (forward: 5'-AATACTGCAAGTGGACaCaGGCCTCTGCCTACCAC-3', reverse: $\quad$ 5'-GTGGTAGGCAGAGGCCțtigTCCACTTGCAGTATT-3'), PPRE5mut (forward: 5'-CAAGTGGACTCTGGCCaCaGCCTACCACTCAGCAG-3', reverse: 5'-CTGC TGAGTGGTAGGCțtigGCCAGAGTCCACTTG-3'), PPRE6mut (forward: 5'-GCCCCAT GCCGGGACCạTaGTTCTGATTAGAGTAT-3', reverse: 5'-ATACTCTAATCAGAACțatg GTCCCGGCATGGGGC-3'), PPRE7mut (forward: 5'-ATTATAAAATAAçAAACAtaGGGC AAACACAGTGAT-3', reverse: 5'-ATCACTGTGTTTGCCCaTGTTTgTTATTTTATAAT$\left.3^{\prime}\right)$. The mutant constructs were controlled for the intended mutations and the absence of any 163 unexpected mutations by DNA sequencing. 


\subsection{Transient transfection}

Transient transfection was performed as described recently in more detail [23]. In brief,

HepG2 cells were transiently transfected with $50 \mathrm{ng}$ of the generated reporter gene constructs and co-transfected with 50 ng of both, mouse PPAR $\alpha$ expression plasmid (pCMX-mPPAR $\alpha$ ) and mouse RXR $\alpha$ expression plasmid (pCMX-mRXR $\alpha$ ) (both, generous gifts from R.M. Evans, Salk Institute for Biological Studies, San Diego, CA, USA), or 100 ng empty vector (pCMX) using FuGENE 6 transfection reagent (Roche Diagnostics, Mannheim, Germany) according to the manufacturer's protocol. Cells were also co-transfected with pGL4.74 Renilla luciferase (Rluc) (encoding the renilla luciferase reporter gene; Promega), which was used as internal control reporter vector to normalize for differences in transfection efficiency (Promega, Mannheim, Germany). A 3X ACO-PPRE vector (containing three copies of consensus PPRE from the ACO promoter in front of a luciferase reporter gene; a generous gift from Dr. Sander Kersten, Nutrigenomics Consortium, Top Institue (TI) Food and Nutrition, Wageningen, Netherlands) and pGL4.23 vector were transfected as positive and negative controls, respectively. Following transfection, cells were treated with either $50 \mu \mathrm{mol} / \mathrm{L} \mathrm{WY}-$ 14,643 to achieve activation of PPAR $\alpha$ or vehicle only (DMSO $=$ control) for $24 \mathrm{~h}$. Afterwards, cells were washed with phosphate-buffered saline and lysed with passive lysis buffer (Promega). Luciferase activities were determined with the Dual-Luciferase Reporter Assay System from Promega according to the manufacturer's instructions using a Mithras LB940 luminometer (Berthold Technologies, Bad Wildbad, Germany) as described recently in more detail [23].

\subsection{Electrophoretic mobility shift assay (EMSA)}

EMSA experiments were performed as described recently in more detail [6]. In brief, mouse PPAR $\alpha$ and $\mathrm{RXR} \alpha$ proteins were generated from the expression vectors by in vitro transcription/translation using $\mathrm{TNT}^{\circledR}$ Quick Coupled Transcription/Translation Systems 
191

(Promega) according to the manufacturer's protocol. The following oligonucleotides were annealed with annealing buffer (10 mM Tris, $1 \mathrm{mM}$ EDTA, $0.1 \mathrm{mM} \mathrm{NaCl}$; pH 8.0): BBDPPRE6 (forward: 5'-GACTGCCCCATGCCGGGACCTTTGTTCTGATTAGAGTAT-3', reverse: 5'-AGCTATACTCTAATCAGAACAAAGGTCCCGGCATGGGGC-3'), BBDPPRE6mut for for mutation

(forward: $5^{\prime}-$ GACTGCCCCATGCCGGGACCạTaGTTCTGATTAGAGTAT-3', reverse: 5'AGCTATACTCTAATCAGAACtAtAGGTCCCGGCATGGGGC-3'), OCTN2-PPRE (mouse OCTN2-PPREint-1) as specific control and for competition (forward: 5'GACTCTGTAAGTAGGTGAAAGGGCATATAACTCTTA-3', reverse: $\quad 5^{\prime}-$ AGCTTAAGAGTTATATGCCCTTTCACCTACTTACAG-3'), and OCTN2-PPREmut (mouse OCTN2-PPREint-1mut) as non-specific control (forward: 5'GACTCTGTAAGTAGGTGtattGGGCATATAACTCTTA-3', reverse: 5'AGCTTAAGAGTTATATGCCCạTaCACCTACTTACAG-3'). After annealing, 100 ng double-stranded DNA-probes were labelled with $0.05 \mathrm{mM}$ DIG-ddUTP in 1X labelling buffer (0.2 M potassium cacodylate, $25 \mathrm{mM}$ Tris- $\mathrm{HCl}, 0.25 \mathrm{ng} / \mathrm{mL}$ bovine serum albumin; $\mathrm{pH}$ 6.6), 5 $\mathrm{mM} \mathrm{CoCl} 2,20 \mathrm{U} / \mathrm{uL}$ Terminal transferase (Roche) and incubated for $15 \mathrm{~min}$ at $37^{\circ} \mathrm{C}$. Then 2 $\mu \mathrm{L}$ of each in vitro-translated PPAR $\alpha$ and $\mathrm{RXR} \alpha$ proteins were incubated with $1.6 \mathrm{ng}$ DIGlabelled probes and 5-, 10- and 50-fold molar excess of unlabelled specific probes (OCTN2PPRE) for competition in $1 \mu \mathrm{g}$ poly d(I-C) and EMSA binding buffer (10 mM Tris-HCl, 120 $\mathrm{mM} \mathrm{KCl}, 0.5 \mathrm{mM}$ EDTA, $0.1 \%$ Triton-X-100, 12.5\% glycerol, $0.2 \mathrm{mM}$ DTT) for $20 \mathrm{~min}$ at 211 RT. The protein-DNA complexes were subjected to electrophoresis on $6 \%$ native 212 polyacrylamid gels, and transferred to a positive charged nylon membrane. The DIG-labelled 213 DNA was detected by chemiluminescence using Anti-Digoxigenin-AP Conjugate and CSPD 214 (both from Roche) according to the manufacturer's protocol, and a Bio-Imaging system. 
Numerical data of were analyzed by one-way ANOVA using the Minitab Statistical Software Rel. 13.0 (Minitab, State College, PA, USA). Differences of $P<0.05$ were considered to be significant.

\section{Results}

\subsection{In silico-analysis of mouse BBD promoter for the existence of putative PPRE}

To examine, whether the mouse BBD gene contains putative PPRE, we performed in silico-analysis of an approximately $1.5 \mathrm{~kb}$ nucleotide sequence upstream of the translation start site of BBD gene using NUBIScan software. According to this, this DNA fragment contained seven putative PPRE located at positions -17 to -29 (PPRE4), -24 to -36 (PPRE5), 75 to -87 (PPRE6), -212 to -224 (PPRE7), -355 to -367 (PPRE1), -824 to -839 (PPRE2) and 1256 to -1268 (PPRE3) relative to the transcription start site. The sequence alignment between the consensus PPRE AGGTCAAAGGTCA (termed DR-1: direct repeat-1) and the predicted PPRE in the mouse BBD promoter showed high similarity. Sequence alignment of PPRE4, PPRE5, PPRE6, PPRE7, PPRE2 and PPRE3 between mouse (promoter) and rat (intron1) showed high similarity (Tab. 2). In addition, sequence alignment of PPRE4, PPRE5, PPRE6 and PPRE7 between mouse (promoter) and human (intron2) also revealed high similarity. Alignment of PPRE1 revealed only a very low sequence identity between mouse, rat and human (Tab. 2).

\subsection{Transcriptional activity of putative PPRE in the mouse BBD promoter}

To evaluate, whether the putative PPRE in the mouse BBD promoter are responsible for PPAR $\alpha$-mediated transactivation of $\mathrm{BBD}$, we generated four plasmid constructs containing 5'-deleted fragments of mouse BBD promoter upstream of a firefly luciferase reporter gene. These constructs were transiently transfected into HepG2 cells with cotransfection of either $\mathrm{pCMX}-\mathrm{mPPAR} \alpha$ and $\mathrm{pCMX}-\mathrm{mRXR} \alpha$ or empty vector (pCMX), and, 
subsequently, cells were treated with or without the PPAR $\alpha$ agonist WY-14,643. As shown in

244 Fig. 1, there was a significant increase in luciferase activity in response to co-expression of mouse PPAR $\alpha$ and RXR $\alpha$ and/or WY-14,643 in cells transfected with either the full-length BBD construct 1 or the truncation constructs BBD construct 2 and BBD construct 3 , in which

PPRE3 and PPRE2, respectively, were serially deleted $(P<0.05)$. The fold increases in luciferase activity in response to co-expression of mouse PPAR $\alpha / \mathrm{RXR} \alpha$ and/or WY-14,643 were similar between these three constructs compared to the full-length construct BBD construct 1 indicating that PPRE3 and PPRE2 are of minor importance for regulation of mouse BBD by PPAR $\alpha$. In cells transfected with the truncation BBD construct 4 , in which PPRE1 was deleted, basal luciferase activity (without co-expression of mouse PPAR $\alpha / R X R \alpha$ and WY-14,643) was significantly lower when compared to the full-length BBD construct 1. However, the response of this construct to co-expression of mouse PPAR $\alpha / \mathrm{RXR} \alpha$ and/or WY14,643 was similar strong as observed with the full-length construct indicating that PPRE1 is also not of importance for PPAR $\alpha$-dependent regulation of mouse BBD. To further confirm our assumptions, we generated mutant constructs from the truncation reporter constructs each containing targeted mutations in PPRE3, PPRE2 and/or PPRE1. As shown in Fig. 1, cells transfected with mutant constructs harboring a single mutation in either PPRE3 or PPRE2 had a similar basal luciferase activity and showed a similar response to mouse PPAR $\alpha / R X R \alpha$ and/or WY-14,643 compared to cells transfected with the corresponding wild-type constructs. Cells transfected with a mutant construct with a single mutation in PPRE1 had a markedly lower basal reporter activity than cells transfected with the corresponding wild-type BBD construct 3 (Fig. 1) but the response to mouse PPAR $\alpha / \mathrm{RXR} \alpha$ and/or WY-14,643 was similar as observed in cells transfected with the corresponding wild-type construct. These results confirmed that PPRE3, PPRE2 and PPRE1 probably do not contribute to the PPAR $\alpha-$ dependent regulation of mouse BBD. However, we observed that the reporter activity of BBD construct 4, which lacks PPRE1, PPRE2 and PPRE3, was still increased by co-expression of 
mouse PPAR $\alpha / R X R \alpha$ and/or WY-14,643 and the response to mouse PPAR $\alpha / R X R \alpha$ and/or WY-14,643 was similar strong as that of BBD construct 1, BBD construct 2 and $\mathrm{BBD}$ construct 3 (Fig. 1). Thus, these findings suggested that a functional PPRE might be located in the more proximal region of the BBD promoter.

To identify this functional PPRE, we generated additional truncation reporter constructs in which the remaining PPRE7, PPRE6, PPRE5 and PPRE4 were either serially deleted or mutated. As shown in Fig. 2, serial deletion of PPRE1 and PPRE7 reduced basal luciferase reporter activity but did not impair the response to mouse PPAR $\alpha / \operatorname{RXR} \alpha$ and/or WY-14,643 which confirms the results from the experiment shown in Fig. 1. However, when PPRE6 was either deleted (BBD construct 6) or mutated, basal reporter activity was dramatically reduced compared to BBD construct 3 and the response of the reporter activity to mouse PPAR $\alpha / \mathrm{RXR} \alpha$ and/or WY-14,643 was completely abolished indicating that PPRE6 is functional, whereas PPRE7, PPRE5, PPRE4 and PPRE1 are not functional (Fig. 2). The same loss of responsiveness to mouse PPAR $\alpha / \mathrm{RXR} \alpha$ and/or WY-14,643 was observed when, in addition to PPRE6, PPRE1 was mutated (Fig. 2). Confirming that PPRE7, PPRE5, PPRE4 and PPRE1 are not functional, no impairment in the reporter response to mouse PPAR $\alpha /$ RXR $\alpha$ and/or WY-14,643 was found when either PPRE7, PPRE5, PPRE4 or PPRE1 were mutated (Fig. 2).

To further proof the importance of PPRE6 for PPAR $\alpha$-dependent regulation of mouse $\mathrm{BBD}$, we generated a reporter gene construct containing 3 copies of PPRE6 in front of the mini promoter of the luciferase reporter vector. As shown in Fig. 3, cells transfected with this construct showed a pronounced response to co-expression of mouse PPAR $\alpha / R X R \alpha$ and WY291 14,643, whereas cells transfected with reporter constructs containing multiple copies of either 292 PPRE1 or PPRE3 showed no response at all. To provide final proof for the importance of PPRE6 for PPAR $\alpha$-dependent regulation of mouse BBD, we transfected cells with the full length BBD construct 1 bearing a mutation in PPRE6. The response of the reporter activity of 
295 this construct to mouse PPAR $\alpha / \mathrm{RXR} \alpha$ and/or WY-14,643 was completely abolished

indicating that PPRE6 is functional.

\subsection{In vitro-binding of PPAR $/ R X R \alpha$ heterodimer to PPRE6 of mouse BBD promoter}

To finally confirm the functionality of PPRE6, we studied in vitro-binding of mouse PPAR $\alpha / \mathrm{RXR} \alpha$ to PPRE6 of mouse BBD promoter using in vitro-translated mouse PPAR $\alpha / R X R \alpha$ and an oligonucleotide corresponding to PPRE6 in gel shift assays (EMSA). As shown in Fig. 4, a major DNA-protein complex was formed between the specific probe of mouse OCTN2-PPREint1 and the in vitro-translated PPAR $\alpha / \mathrm{RXR} \alpha$ heterodimer as positive control (lane 4; Fig. 4), whereas no complex was formed between the mutant non-specific probe OCTN2-PPREint1_mut and in vitro-translated PPAR $\alpha / \mathrm{RXR} \alpha$ heterodimer as negative control (lane 5; Fig. 4). A strong DNA-protein complex formation was also observed between the specific probe of mouse BBD-PPRE6 and in vitro-translated PPAR $\alpha / \mathrm{RXR} \alpha$ heterodimer (lane 6; Fig. 4). In addition, competition experiments using the oligonucleotide corresponding to mouse BBD-PPRE6 and 5-, 10- and 50-fold molar excess of unlabelled specific probes (OCTN2-PPREint1) were performed to test the specificity of PPAR $\alpha / R X R \alpha$ binding (lanes 7 , 8 and 9; Fig. 4). As demonstrated in Fig. 4, the complex intensity was successively reduced with increasing molar excess of unlabelled specific probe. At 50-fold molar excess of 313 unlabelled probe, complex formation was almost completely absent being indicative of 314 complete competition. No DNA-protein complex formation was observed between the mutant 315 oligonucleotide PPRE6mut and in vitro-translated PPAR $\alpha /$ RXR $\alpha$ heterodimer (lane 10; Fig. 316 4). These results demonstrated that PPAR $\alpha / R X R \alpha$ heterodimer binds specifically to PPRE6 of 317 mouse BBD.

\section{Discussion}


Although convincing evidence from studies with PPAR $\alpha$-deficient mice existed [11, $12,15]$ suggesting that the carnitine biosynthetic enzyme BBD is regulated by PPAR $\alpha$, the identification of BBD as a direct PPAR $\alpha$ target gene as well as its exact regulation remained to be demonstrated. To clarify this, we performed in silico-analysis of the mouse BBD promoter using NUBIScan software, and found seven putative PPRE with high similarity to the known consensus PPRE sequence in an approximately $1.5 \mathrm{~kb}$ fragment of mouse BBD promoter. In order to explore their functional relevance for transcriptional regulation of mouse BBD by PPAR $\alpha$, we created different serial 5'-truncation BBD promoter reporter constructs containing a different number of putative PPRE and tested their responsiveness to exogenous mouse PPAR $\alpha / \mathrm{RXR} \alpha$ and $\mathrm{WY}-14,643$ in reporter gene assays. Using this approach we found that the two PPRE most distant from the translation start site (PPRE3 and PPRE2) are not of importance for the regulation of $\mathrm{BBD}$ by $\mathrm{PPAR} \alpha$ because the responsiveness of the corresponding truncation constructs without PPRE3 and PPRE2 to exogenous mouse PPAR $\alpha / R X R \alpha$ and WY-14,643 did not differ from that of the full-length reporter construct (BBD construct 1). To confirm that PPRE3 and PPRE2 are not functional we also tested the responsiveness of truncation constructs harboring a selective mutation in either PPRE3 or PPRE2, and indeed found that their responsiveness to both, exogenous PPAR $\alpha / R X R \alpha$ and WY-14,643 did not differ from that of the non-mutated construct. When analyzing the responsiveness of the next truncation construct, in which, in addition to PPRE3 and PPRE2, PPRE1 was deleted, we observed a marked loss in the basal reporter activity (without exogenous PPAR $\alpha / R X R \alpha$ and WY-14,643) but the response to exogenous PPAR $\alpha / R X R \alpha$ and WY-14,643 was similar as that of the full-length construct indicating that PPRE1 is also not of importance for PPAR $\alpha$-dependent regulation of the mouse BBD promoter. Since the truncation construct without PPRE1 (BBD construct 4) and all truncation reporter constructs with a selective mutation in PPRE1 were still similar responsive to exogenous PPAR $\alpha / R X R \alpha$ and WY-14,643 as the full-length reporter construct and the truncation reporter constructs 
containing PPRE3 and PPRE2, we concluded that one or more of the remaining putative PPRE (PPRE4, PPRE5, PPRE6 and PPRE7) located in the more proximal region of the BBD promoter are functional. To test this, we created further truncated and mutated reporter constructs where the remaining PPRE were either serially deleted or mutated. According to this, we observed that mutating PPRE6 resulted in a complete loss of responsiveness to both, exogenous mouse PPAR $\alpha / \mathrm{RXR} \alpha$ and WY-14,643 indicating that PPRE6 is a functional PPRE in the mouse BBD promoter. The same complete loss of responsiveness to exogenous mouse PPAR $\alpha / R X R \alpha$ and WY-14,643 was observed when both, PPRE1 and PPRE6 were mutated.

The key role of PPRE6 for transcriptional regulation of the mouse BBD promoter by PPAR $\alpha$ could be further evidenced by using reporter constructs, in which PPRE6 was either mutated (BBD construct 5) or deleted (BBD construct 6). In these constructs, the basal reporter activity was the lowest of all constructs tested and there was no response at all to exogenous mouse PPAR $\alpha / \mathrm{RXR} \alpha$ and WY-14,643. Hence, these observations indicated that the two most proximal PPRE, PPRE5 and PPRE4, are not functional. This was also confirmed by testing the responsiveness of truncation constructs harboring a selective mutation in either PPRE5 or PPRE4. A further strong evidence for the key role of PPRE6 in the regulation of mouse BBD promoter was provided from experiments using a reporter construct containing multiple copies of PPRE6 in front of the luciferase reporter gene. Cells transfected with this construct showed a marked response to exogenous mouse PPAR $\alpha / \mathrm{RXR} \alpha$ and WY-14,643, whereas cells transfected with constructs containing multiple copies of either PPRE1 or PPRE3 did not show any response at all. Collectively, these results from reporter gene experiments indicated that PPRE6 is essential for regulation of mouse BBD by PPAR $\alpha$. Moreover, these data demonstrate that the other PPRE predicted from NUBIScan analysis are obviously not functional and probably of minor importance for PPAR $\alpha$-dependent regulation of mouse BBD.

To further clarify whether PPRE6 in the BBD promoter is functional and binds the PPAR $\alpha / R X R \alpha$ heterodimer, we performed gel shift assays using in vitro-translated mouse 
PPAR $\alpha / R X R \alpha$ proteins and oligonucleotides representing PPRE6. In the presence of PPAR $\alpha / R X R \alpha$, a strong band representing the DNA-PPAR $\alpha / R X R \alpha$ complex appeared using the PPRE6-containing oligonucleotide, whereas the bands were weaker in the presence of an excess on unlabelled specific oligonucleotide. No band for the DNA-PPAR $\alpha / R X R \alpha$ complex was observed when olinucleotides containing the mutated PPRE6 were used. Although we did not perform antibody supershift assays, these results strongly support our aforementioned assumption that the PPAR $\alpha / \operatorname{RXR} \alpha$ heterodimer binds to PPRE6 of mouse BBD and that PPRE6 is decisive for transcriptional regulation of mouse BBD.

To investigate whether regulation of the BBD gene by PPAR $\alpha$ might be similar between mouse, rat and human, we compared the promoter and intron sequences of these species. According to this, we found that PPRE6 shares a complete (100\%) sequence identity between mouse, rat and human which is indeed indicative of a similar regulation of the BBD gene by PPAR $\alpha$ between these species. Nevertheless, the location of the translation start site of the BBD gene differs between mouse, rat and human. In the rat, the translation start site of the BBD gene is in the second exon (cDNA sequences from FQ210746 and NM_022629, genomic DNA sequences from AC106654), whereas in mice and humans the translation start sites are in the first and third exon, respectively (cDNA sequences from NM_003986 and genomic DNA sequences AC015756). Considering these differences, the exact regulation of the BBD gene by PPAR $\alpha$ might differ, at least partially, between mice, rats and humans. This, however, has to be clarified in future studies.

In conclusion, the present study clearly shows that mouse BBD is a direct PPAR $\alpha$ target gene and that transcriptional up-regulation of mouse BBD by PPAR $\alpha$ is likely mediated by binding of the PPAR $\alpha / R X R \alpha$ heterodimer to a PPRE located in its proximal promoter region. The results confirm emerging evidence from recent studies that PPAR $\alpha$ plays a key role in the regulation of carnitine homeostasis by controlling genes involved in both, carnitine synthesis and carnitine uptake $[11,12,15]$. From a practical point of view, this study indicates 
398 that fibrates, synthetic agonists of PPAR $\alpha$ used in the therapy of hyperlipidemia, might

\section{Acknowledgements}

This work was funded by German Research Foundation (Deutsche

Forschungsgemeinschaft)

\section{References}

1. Desvergne B, Wahli W. Peroxisome proliferator-activated receptors: Nuclear control of metabolism. Endocr Rev 1999;20:649-88.

2. Mandard S, Müller M, Kersten S. Peroxisome proliferator receptor $\alpha$ target genes. Cell Mol Life Sci 2004;61:393-416.

3. Helledie T, Grøntved L, Jensen SS, Kiilerich P, Rietveld L, Albrektsen T, et al. The gene encoding the Acyl-CoA-binding protein is activated by peroxisome proliferator-activated receptor gamma through an intronic response element functionally conserved between humans and rodents. 2002;277:26821-30.

4. Hansmannel F, Clémencet MC, Le Jossic-Corcos C, Osumi T, Latruffe N, NicolasFrancés V. Functional characterization of a peroxisome proliferator response-element located in the intron 3 of rat peroxisomal thiolase B gene. Biochem Biophys Res Commun 2003;311:149-55.

5. Gutgesell A, Wen G, König B, Koch A, Spielmann J, Stangl GI, Eder K, Ringseis R. Mouse carnitine-acylcarnitine translocase (CACT) is transcriptionally regulated by PPAR $\alpha$ and PPAR $\delta$ in liver cells. Biochim Biophys Acta 2009;1790:1206-16.

6. Wen G, Ringseis R, Eder K. Mouse OCTN2 is directly regulated by peroxisome proliferator-activated receptor $\alpha$ via a PPRE located in the first intron. Biochem Pharmacol 2010;79:768-76. 
7. Forman BM, Chen J, Evans RM. Hypolipidemic drugs, polyunsaturated fatty acids, and eicosanoids are ligands for peroxisome proliferator-activated receptors $\alpha$ and $\delta$. Proc Natl Acad Sci USA 1997;94:4312-7.

8. Krey G, Braissant O, L'Horset F, Kalkhoven E, Perroud M, Parker MG, et al. Fatty acids, eicosanoids, and hypolipidemic agents identified as ligands of peroxisome proliferatoractivated receptors by coactivator-dependent receptor ligand assay. Mol Endocrinol 1997;11:779-91.

9. Ringseis R, Eder K. Influence of pharmacological PPAR $\alpha$ activators on carnitine homeostasis in proliferating and non-proliferating species. Pharmacol Res 2009;60:17984.

10. Luci S, Geissler S, Konig B, Koch A, Stangl GI, Hirche F, Eder K. PPAR $\alpha$ agonists upregulate organic cation transporters in rat liver cells. Biochem Biophys Res Commun 2006;350:704-8.

11. van Vlies N, Ferdinandusse S, Turkenburg M, Wanders RJ, Vaz FM. PPAR $\alpha$-activation results in enhanced carnitine biosynthesis and OCTN2-mediated hepatic carnitine accumulation. Biochim Biophys Acta 2007;1767:1134-42.

12. Koch A, König B, Stangl GI, Eder K (2008): PPAR alpha mediates transcriptional upregulation of novel organic cation transporters-2 and -3 and enzymes involved in hepatic carnitine synthesis. Exp Biol Med 233:356-365.

13. Ringseis R, Wege N, Wen G, Rauer C, Hirche F, Kluge H, Eder K. Carnitine synthesis and uptake into cells are stimulated by fasting in pigs as a model of nonproliferating species. J Nutr Biochem 2009;20:840-7.

14. Gutgesell A, Ringseis R, Brandsch C, Stangl GI, Hirche F, Eder K. Peroxisome proliferator-activated receptor $\alpha$ and enzymes of carnitine biosynthesis in the liver are down-regulated during lactation in rats. Metabolism 2009;58:226-32. 
15. Makowski L, Noland RC, Koves TR, Xing W, Ilkayeva OR, Muehlbauer MJ, Stevens RD, Muoio DM. Metabolic profiling of PPARalpha-/- mice reveals defects in carnitine and amino acid homeostasis that are partially reversed by oral carnitine supplementation. FASEB J 2009;23:586-604.

16. McGarry JD, Brown NF. The mitochondrial carnitine palmitoyltransferase system. From concept to molecular analysis. Eur J Biochem 1997;244:1-14.

17. Rebouche CJ, Seim H. Carnitine metabolism and its regulation in microorganisms and mammals. Annu Rev Nutr 1998;18:39-61.

18. Vaz FM, Wanders RJ. Carnitine biosynthesis in mammals. Biochem J 2002;361:417-29.

19. Fischer M, Keller J, Hirche F, Kluge H, Ringseis R, Eder K. Activities of gammabutyrobetaine dioxygenase and concentrations of carnitine in tissues of pigs. Comp Biochem Physiol A Mol Integr Physiol 2009;153:324-31.

20. Tamai I, Ohashi R, Nezu J, Yabuuchi H, Oku A, Shimane M, et al. Molecular and functional identification of sodium iondependent, high affinity human carnitine transporter OCTN2. J Biol Chem 1998;273:20378-82.

21. Lahjouji K, Mitchell GA, Qureshi IA. Carnitine transport by organic cation transporters and systemic carnitine deficiency. Mol Genet Metab 2001;73:287-97.

22. Podvinec M, Kaufmann MR, Handschin C, Meyer UA. NUBIScan, an in silico approach for prediction of nuclear receptor response elements. Mol Endocrinol 2002;16:1269-79.

23. Ringseis R, König B, Leuner B, Schubert S, Nass N, Stangl G, Eder K. LDL receptor gene transcription is selectively induced by t10c12-CLA but not by c9t11-CLA in the human hepatoma cell line HepG2.Biochim Biophys Acta 2006;1761:1235-43. 
472

1

\section{Table 1}

473 Oligonucleotides used for PCR amplification of promoter region of mouse BBD

\begin{tabular}{ll}
\hline Oligonucleotide & Oligonucleotide sequence $\left(5^{\prime}{ }^{\prime} 3^{\prime}\right)$ \\
\hline mBBD_BglII & ATCAGATCTTGTTTCTGGTCTTTGGTGA \\
mBBD_164_XhoI & ATCCTCGAGATGGGGCGAACTGTAGGCT \\
mBBD_232_XhoI & ATCCTCGAGCTTACAGCTAGTCACTGTGC \\
mBBD_376_XhoI & ATCCTCGAGCCATTTGCGTAGCGGTTTTC \\
mBBD_668_XhoI & ATCCTCGAGTCCAGTGAGAAATATACTGTG \\
mBBD_1197_XhoI & ATCCTCGAGTCAGTATCGGATACAGTGAAG \\
mBBD_1488_XhoI & ATCCTCGAGGCACACCATGGGCTAAGAATAT \\
\hline
\end{tabular}


Table 2

\begin{tabular}{ll}
\hline $\begin{array}{l}\text { PPRE } \\
\text { denomination }\end{array}$ & Species \\
\hline Consensus & \\
PPRE & \\
PPRE4 & M. musculus \\
& R. norvegicus \\
& H. sapiens
\end{tabular}

PPRE 5

PPRE 6

PPRE1

PPRE3
M. musculus
$R$. norvegicus
H. sapiens

M. musculus

R. norvegicus

H. sapiens

PPRE7

PPRE2

M. musculus

$R$. norvegicus

H. sapiens

M. musculus

R. norvegicus

H. sapiens

M. musculus

R. norvegicus

H. sapiens

M. musculus

$R$. norvegicus

H. sapiens

Sequence and position*

AGGTCAnAGGTCA

-29 5' AGGCCAgAGTCCA -17prom

85 3'AGGCCAGAGTCCA 73int1

$138245^{\prime}$ AGGCCAGAGTCCA 13836 int2

-36 5' TAGGCAgAGGCCA -24prom

80 3' TAGGCAGAGGCCA 92 int 1

13817 5' ATAGCAGAGGCCA 13829 int2

-87 5' AGAACAaAGGTCC -75prom

131 3'AGAACAAAGGTCC 143int1

$137625^{\prime}$ AGAACAAAGGTCC 13774 int2

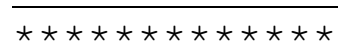

-212 3' AGAAACaAGGGCA -224prom

280 5' AGAAACAATGGCA 268 int 1

13632 3'

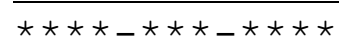

-367 5' AGTTCAaCGGTAG -335prom

416 3'AGCTCAAC----- 423int 1

13486 5'TTTTCAAAAG--- 13495 int2

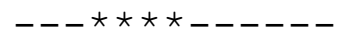

-836 5'AGGTATaCGGTCA -825prom

886 3'AGGTATACAATCA 874 int 1

13210 5'AAATATATAGTCA 13022 int2

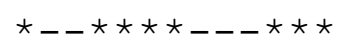

-1256 3' CTGTCAgGGGTCA -1268prom

1313 5'CTGTCAGGGATCA 1301 int 1

$125933^{\prime}$-CATTAAG-ATAA 12603 int2

*Nucleotides of putative PPRE are underlined. Matching nucleotides between mouse, rat and human are shown

by asterisks. Position of PPRE was indicated. 


\section{Legends for figures}

\section{Figure 1}

Effect of exogenous mouse PPAR $/ R X R \alpha$ and PPAR ligand WY-14,643 on transcriptional activity of BBD promoter-truncation reporter constructs

HepG2 cells were transiently transfected with mutated and non-mutated serial 5 '-truncation BBD promoter reporter constructs pGL4-BBD-1488, $-1197,-668$ and -376 , and a renilla luciferase expression vector for normalization. Cells were also co-transfected with or without (empty vector) expression vectors for mouse PPAR $\alpha$ and RXR $\alpha$. After transfection, cells were stimulated or not with $50 \mu \mathrm{M}$ of WY-14,643 for $24 \mathrm{~h}$. Afterwards, cells were lysed, and luciferase activities of the BBD promoter-truncation reporter vectors and the renilla luciferase expression vector determined by dual luciferase assay. Results represent means \pm SEM for one out of three independent experiments each performed in triplicate.

\section{Figure 2}

Effect of exogenous mouse PPAR $\alpha / R X R \alpha$ and PPAR ligand WY-14,643 on transcriptional activity of BBD promoter-truncation reporter constructs

HepG2 cells were transiently transfected with mutated and non-mutated serial 5 '-truncation BBD promoter reporter constructs pGL4-BBD-668, -376, 232 and -164, and a renilla luciferase expression vector for normalization. Cells were also co-transfected with or without (empty vector) expression vectors for mouse PPAR $\alpha$ and RXR $\alpha$. After transfection, cells were stimulated or not with $50 \mu \mathrm{M}$ of WY-14,643 for $24 \mathrm{~h}$. Afterwards, cells were lysed, and luciferase activities of the BBD promoter-truncation reporter vectors and the renilla luciferase expression vector determined by dual luciferase assay. Results represent means \pm SEM for one out of three independent experiments each performed in triplicate. 


\section{Figure 3}

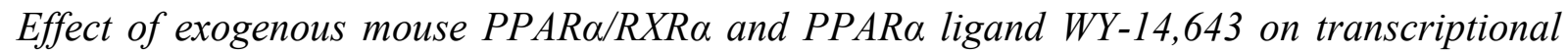
activity of $3 X$ PPRE BBD-promoter reporter constructs

HepG2 cells were transiently transfected with BBD promoter reporter constructs containing 3 copies of either PPRE6, PPRE1 or PPRE3 in front of the TK promoter of the luciferase reporter vector, and a renilla luciferase expression vector for normalization. Cells were also co-transfected with or without (empty vector) expression vectors for mouse PPAR $\alpha$ and RXR $\alpha$. After transfection, cells were stimulated or not with $50 \mu \mathrm{M}$ of WY-14,643 for $24 \mathrm{~h}$. Afterwards, cells were lysed, and luciferase activities of the BBD promoter reporter vectors and the renilla luciferase expression vector determined by dual luciferase assay. Results represent means \pm SEM for one out of three independent experiments each performed in triplicate.

\section{Figure 4}

Binding of in vitro-translated mouse PPAR $\alpha / R X R \alpha$ to the PPRE6 of mouse BBD promoter EMSA was performed using in vitro-translated mouse PPAR $\alpha / \mathrm{RXR} \alpha$ and DIG-labelled oligonucleotide corresponding to either wild-type or mutated PPRE6. Fold molar excess of unlabelled specific probe for competition (OCTN2-PPREint1 oligonucleotide) is indicated. The use of DIG-labelled specific probe (OCTN2-PPRE1int1 oligonucleotide) and nonspecific probe (mutant OCTN2int1mut oligonucleotide) is also indicated. 


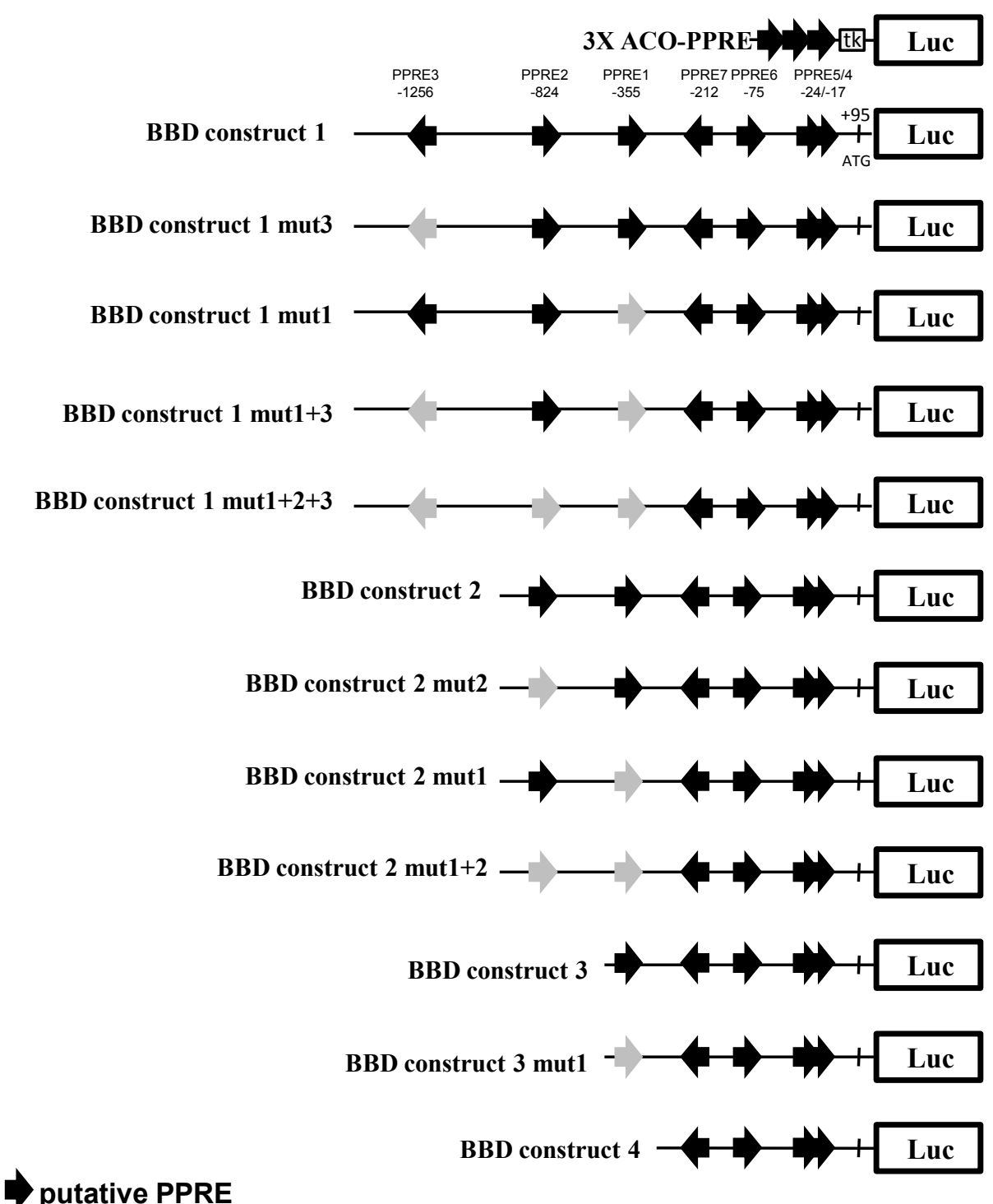

Fig. 1

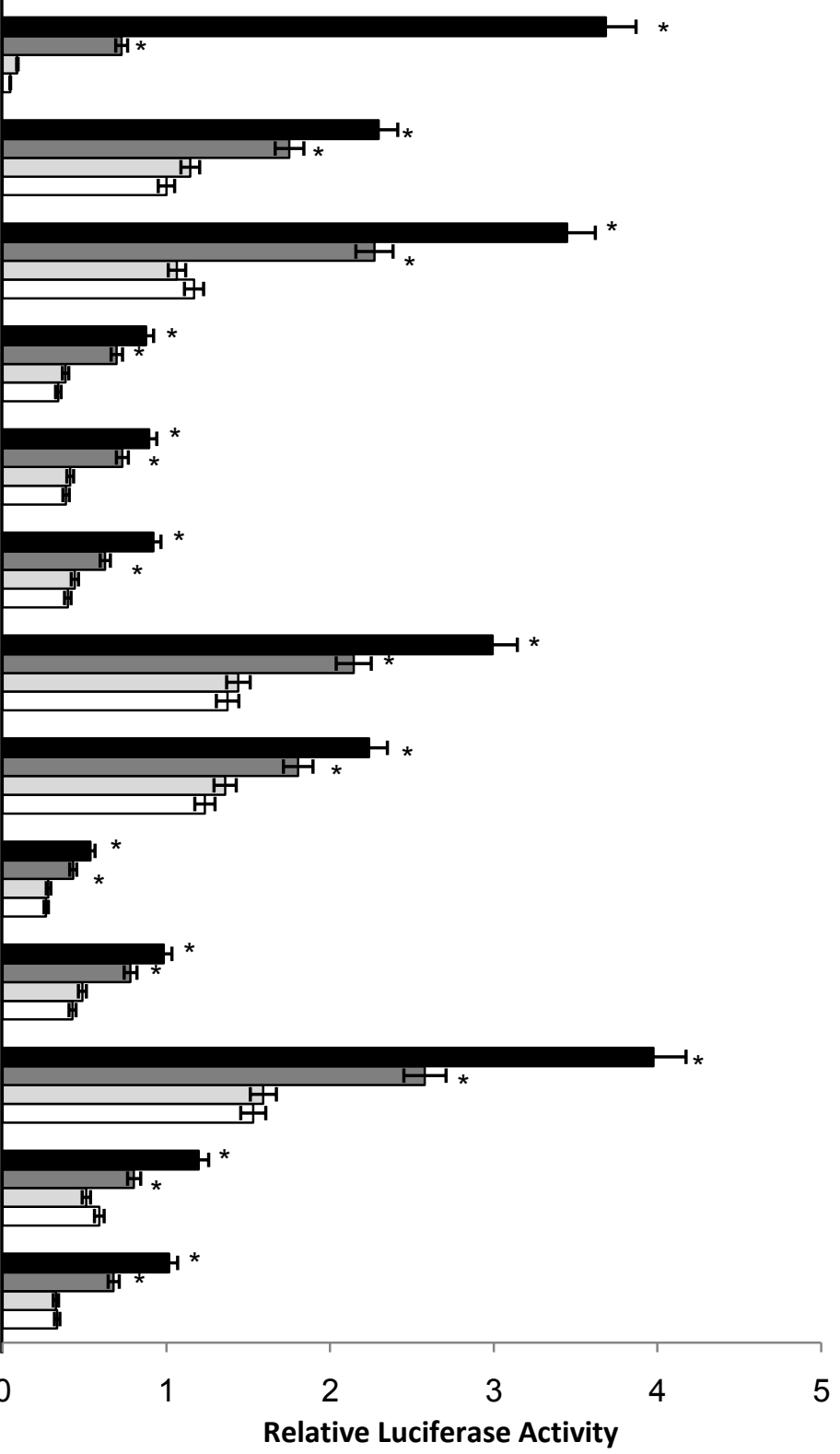


Figure 2

putative PPRE

mutated putative PPRE

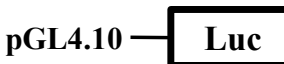

3X ACO-PPREA

PPRE7 PPRE6 PPRE5/4

$\begin{array}{lllll}-335 & -212 & -75 & -24 /-17 & +95\end{array}$
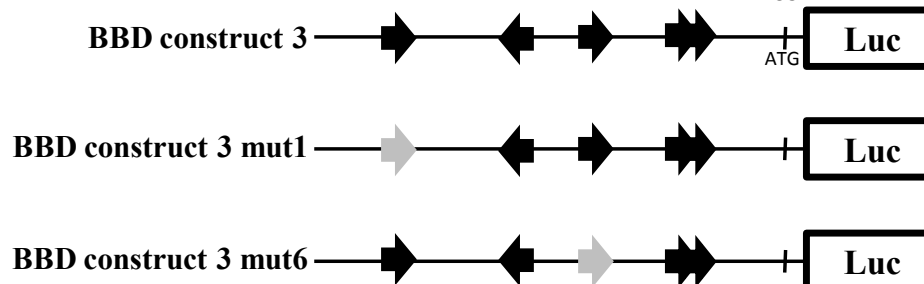

BBD construct 3 mut1+
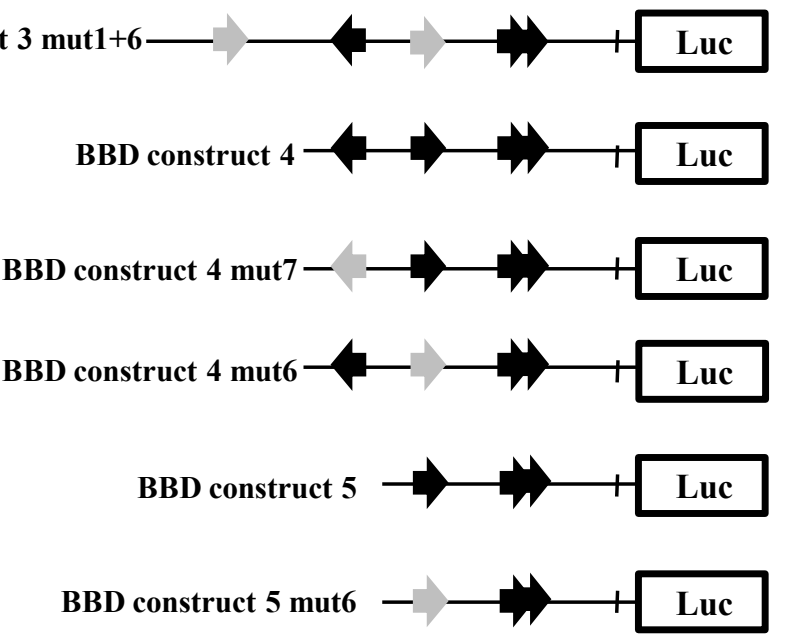

BD construct 6

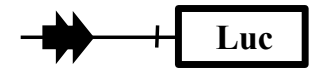

BBD construct 6 mut5 - -+ Luc

BBD construct 6 mut4

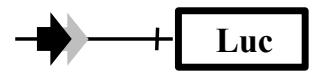

B

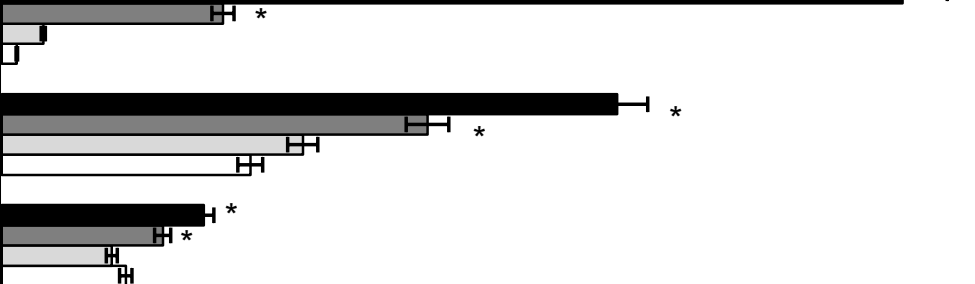

\section{Fig. 2}

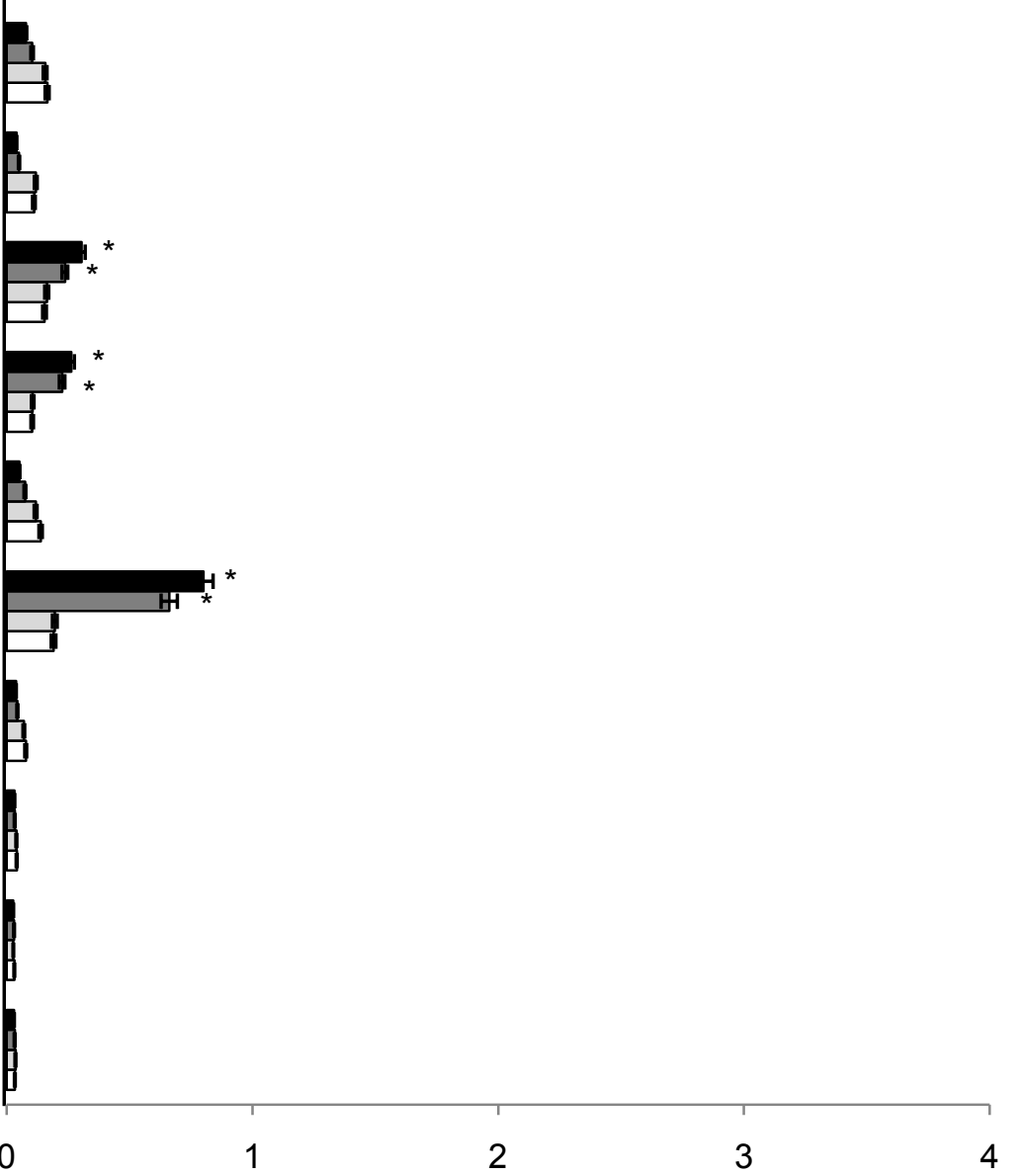




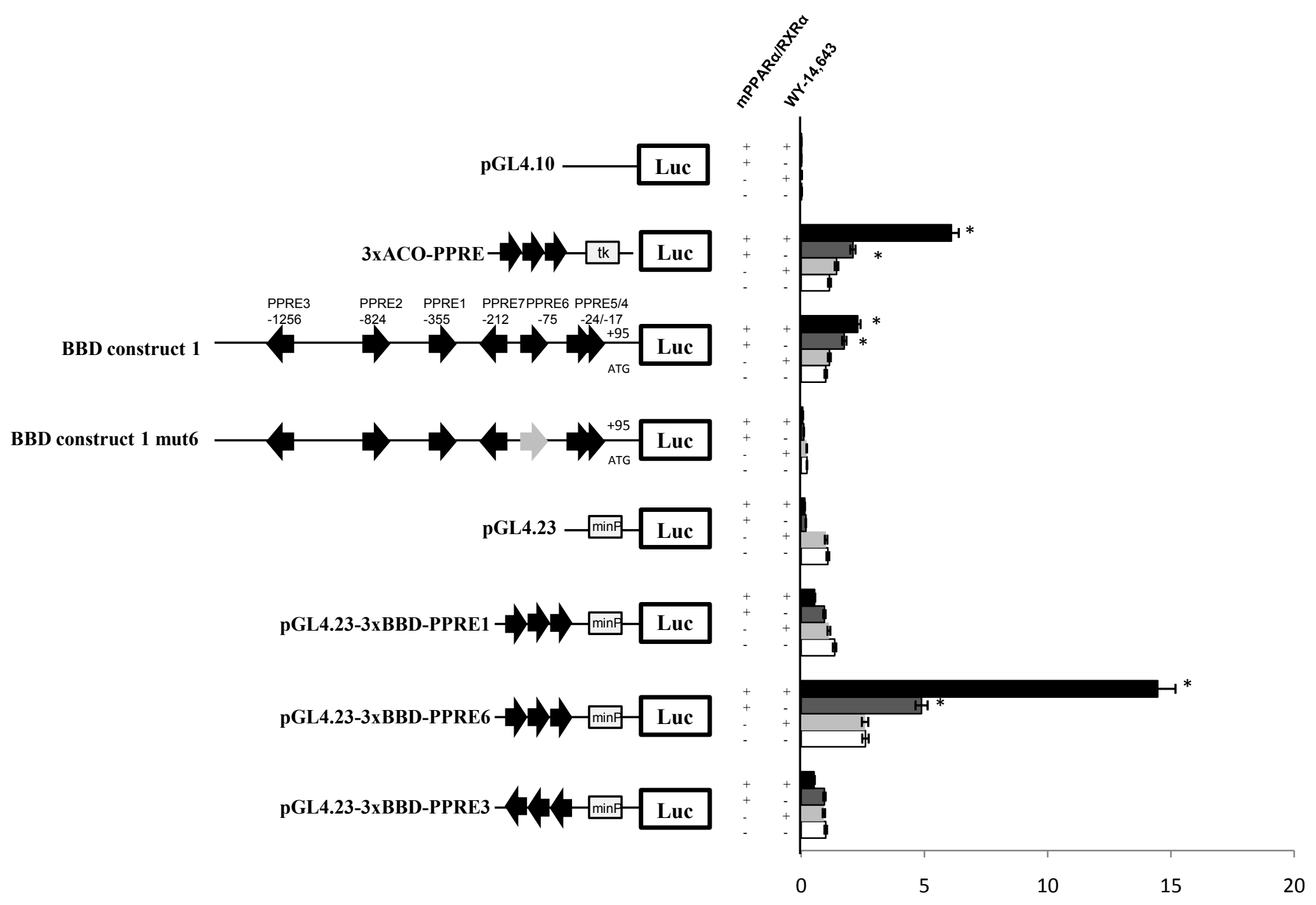

7 putative PPRE

mutated putative PPRE

Fig. 3 
Figure 4

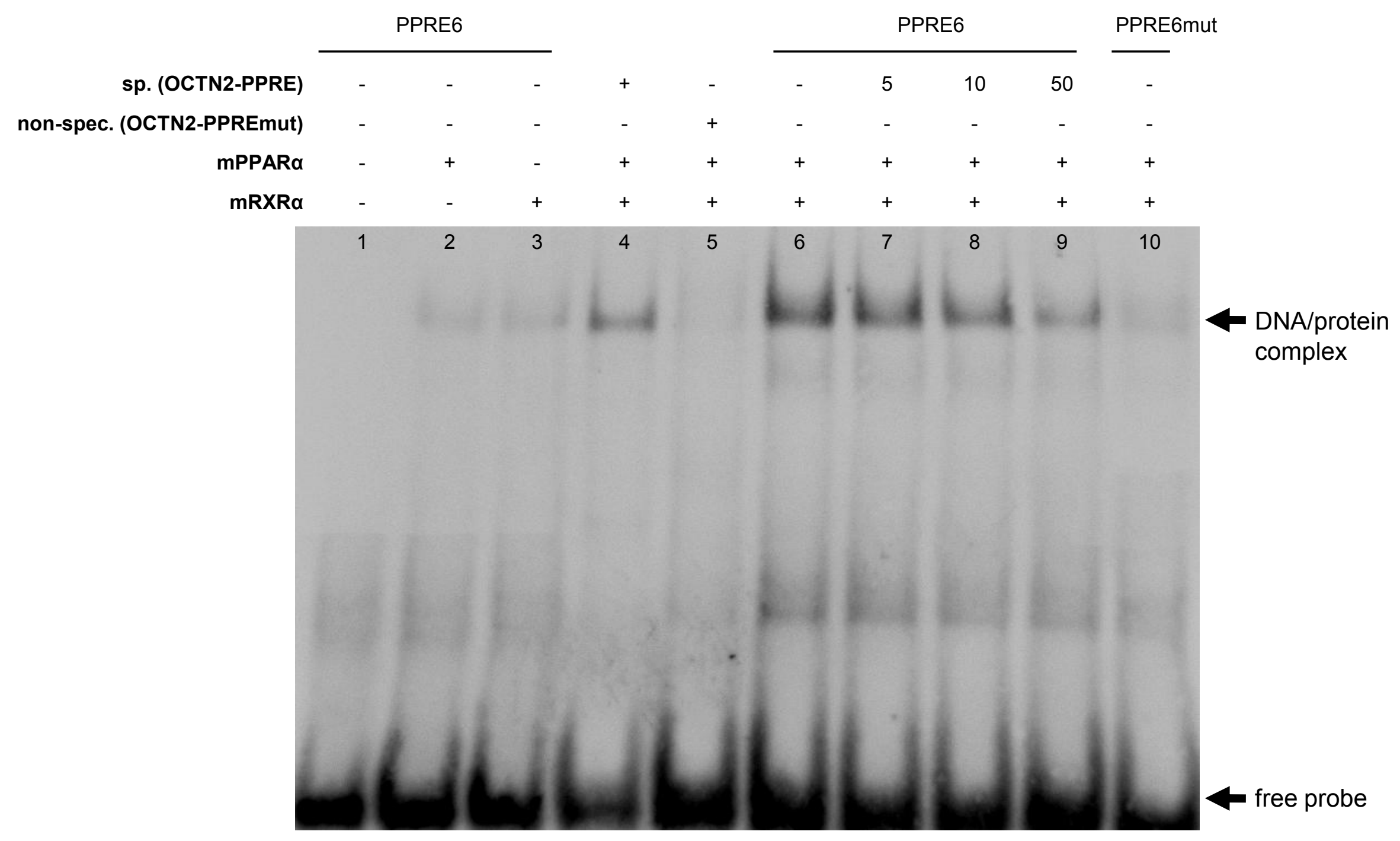

Fig. 4 


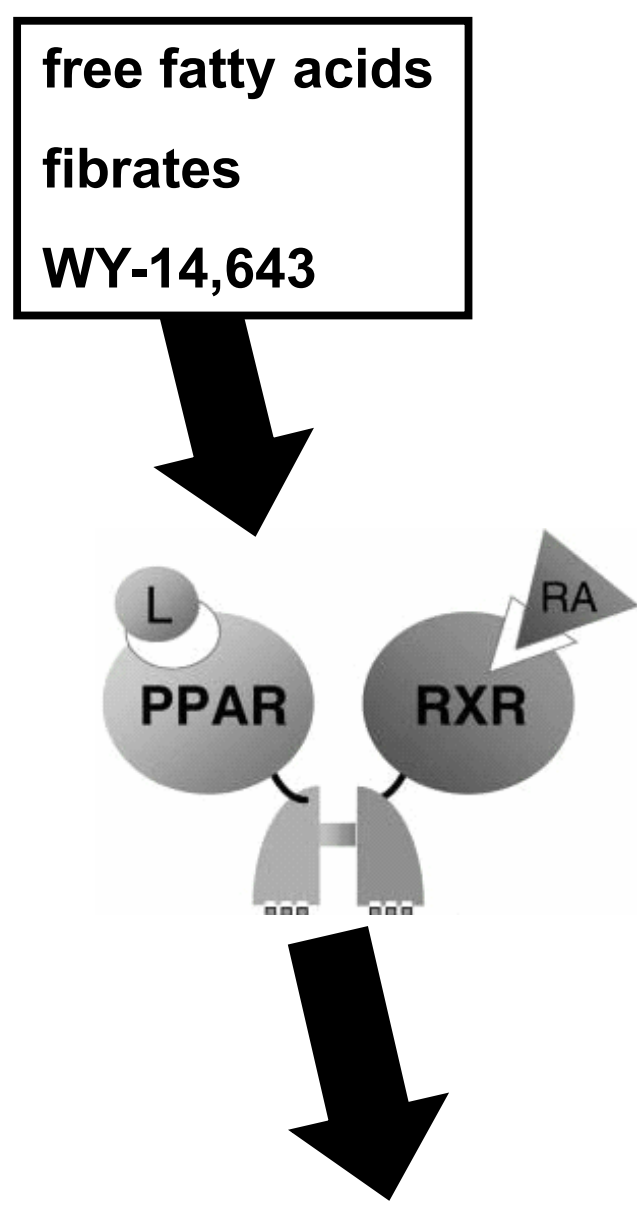

5'

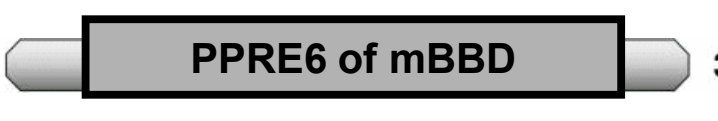

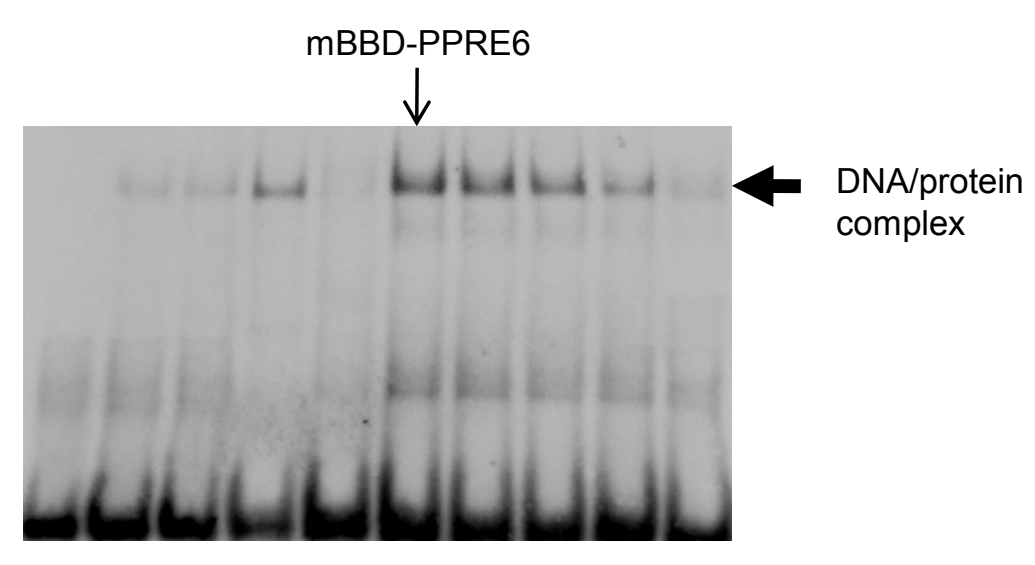

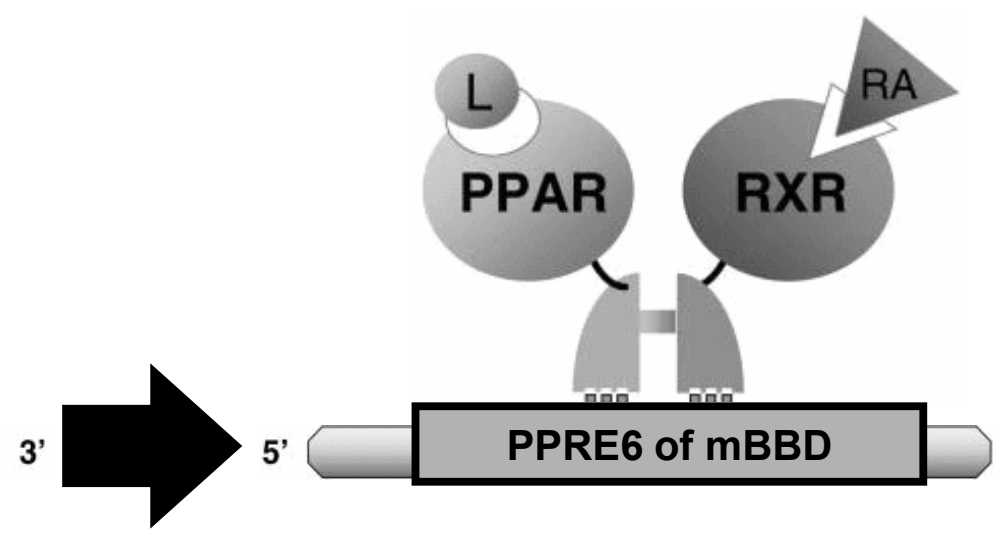

BBD mRNA

Van Vlies et al. 2007 Koch et al. 2008 